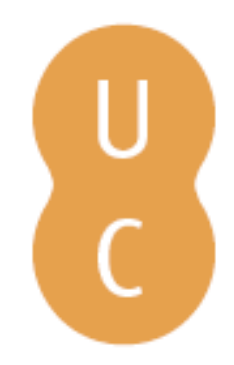

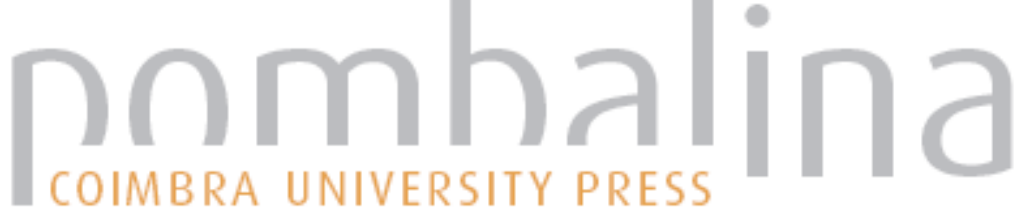

\section{Assessment of biological maturation in adolescent athletes: application of different methods with soccer and hockey players}

\author{
Silva, Manuel J. Coelho e; Simões, Filipe; Santos, João Valente dos; \\ Autor(es): $\quad$ Vaz, Vasco; Figueiredo, António J.; Peña Reyes, Maria E.; Malina, \\ Robert M.
}

Publicado por: Imprensa da Universidade de Coimbra

URL persistente:

URI:http://hdl.handle.net/10316.2/38849

DOI:

DOI:http://dx.doi.org/10.14195/978-989-26-1169-3_2

Accessed : $\quad$ 26-Apr-2023 12:23:23

A navegação consulta e descarregamento dos títulos inseridos nas Bibliotecas Digitais UC Digitalis, UC Pombalina e UC Impactum, pressupõem a aceitação plena e sem reservas dos Termos e Condições de Uso destas Bibliotecas Digitais, disponíveis em https://digitalis.uc.pt/pt-pt/termos.

Conforme exposto nos referidos Termos e Condições de Uso, o descarregamento de títulos de acesso restrito requer uma licença válida de autorização devendo o utilizador aceder ao(s) documento(s) a partir de um endereço de IP da instituição detentora da supramencionada licença.

Ao utilizador é apenas permitido o descarregamento para uso pessoal, pelo que o emprego do(s) título(s) descarregado(s) para outro fim, designadamente comercial, carece de autorização do respetivo autor ou editor da obra.

Na medida em que todas as obras da UC Digitalis se encontram protegidas pelo Código do Direito de Autor e Direitos Conexos e demais legislação aplicável, toda a cópia, parcial ou total, deste documento, nos casos em que é legalmente admitida, deverá conter ou fazer-se acompanhar por este aviso. 


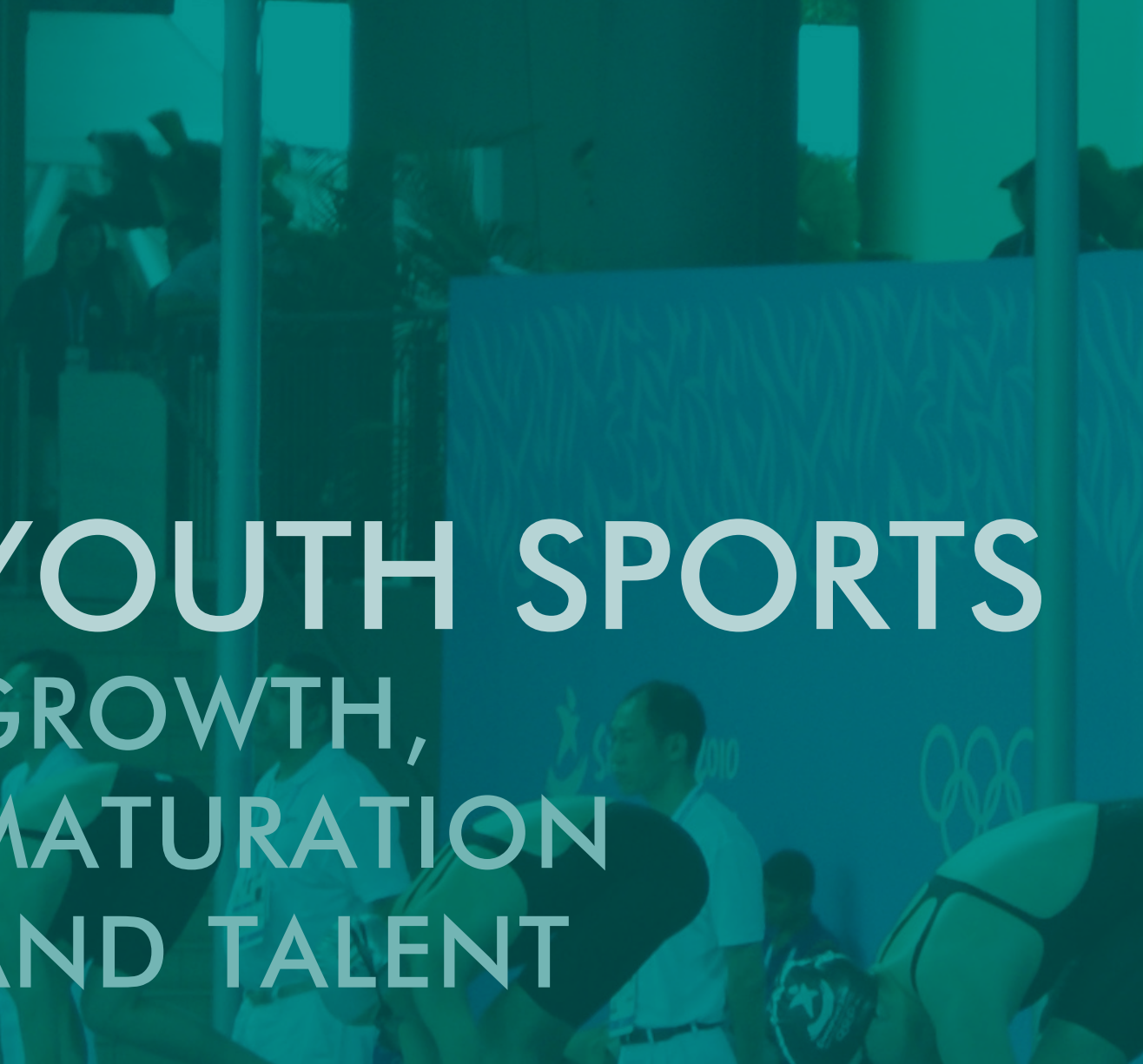

MANUEL J. COELHO E SILVA ANTÓNIO J. FIGUEIREDO MARIJE T. ELFERINK-GEMSER ROBERT M. MALINA

\section{EDITORS}

2. ' EDIÇÃO

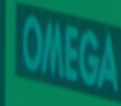

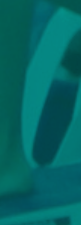




\title{
CHAPTER 2: ASSESSMENT OF BIOLOGICAL MATURATION IN ADOLESCENT ATHLETES - application of different methods with soccer and hockey players
}

\author{
Manuel I Coelho e Silva \\ Filipe Simões \\ João Valente dos Santos \\ Vasco Vaz \\ António J Figueiredo \\ Maria E. Peña Reyes \\ Robert M Malina
}

\section{INTRODUCTION}

Biological maturation is the process that marks progress toward maturity or adulthood. The process varies in tempo, i.e., rate, and timing, i.e., when certain events occur. Inter-individual differences in the tempo and timing of maturation are considerable. Differences among methods for assessing maturation are also apparent and can be considerable. Maturation of the skeleton spans the entire interval from the prenatal state to a fully ossified or mature skeletal. Sexual maturation refers to the secondary sex characteristics which become initially apparent in late childhood and progress towards the mature state during the adolescent years. As used in growth studies, somatic maturation refers to either the percentage of mature height attained at a given age or the timing of maximum growth in height during the adolescent spurt. When a youngster is observed at a single point in time, indicators of skeletal or sexual maturation provide a record of his/her maturity status. Longitudinal observations that span adolescence are needed to obtain an estimate of somatic maturation (Malina et al., 2004). Protocols for the estimation or mature or adult height have a long tradition in growth studies, but prediction equations required an estimate of skeletal age. More recently, equations for the prediction mature height that do not require an estimate of skeletal age and for the prediction of age at maximum growth in height (peak height velocity) have been developed (Roche et al., 1983; Khamis \& Roche, 1994; Mirwald et al., 2002). Skeletal, sexual and somatic maturation are reasonably well-related during adolescence (Nicolson \& Hanley, 1953; Bielicki et al., 1984; Bayer and Bayley, 1959; Malina et al., 2004); however, studies incorporating estimates of somatic maturation based on the more recently developed prediction protocols are not available. 
The impact of individual differences in the timing of biological maturation among boys body size and functional capacities is well documented (Malina et al., 2004). Boys who are advanced in maturity status are not only taller and heavier but also tend to perform better in tasks requiring strength, power and speed compared with age peers who are average ("on time") or late in maturation. This translates to youth sports since adolescent male athletes in several sports, for example, baseball, American football, ice hockey, soccer and track and field, tend to be, on average, advanced in biological maturation compared to peers (Malina, 1994; Malina et al., 2004). As such, it is important to be able to monitor the maturity status of youth involved in sport.

Methods of assessing maturity status vary as do their application. Progress in development of methods of assessment has drawn attention to the need for systematic evaluation of the concordance among methods. In other words, do different methods provide the same indication of maturity status? The answer, in general, is yes (Malina et al., 2004).

This chapter summarizes three studies dealing with the concordance ofdifferent maturity assessments in Portuguese male adolescent athletes. The first addresses the concordance between clinical examination and selfassessment of sexual maturity status in soccer players 11-14 years of age (Coelho e Silva et al., 2005a). The second examines the concordance of classifications of maturity status based on two methods of skeletal age assessment in soccer players 13-15 years (Coelho e Silva et al., 2009). And the third examines the validity of predicted adult height without skeletal age in roller hockey players 14.8- 16.5 years of age (Coelho e Silva et al., 2008).

\section{PUBIC HAIR SELF-ASSESSMENT IN SOCCER PLAYERS}

The assessment of sexual maturity in boys is based on secondary sex characteristics - genitalia and and pubic hair. The most commonly used criteria are those described by Tanner (1962). Applications to young athletes have more often used stages of pubic hair $(\mathrm{PH})$ development. Stage I indicates the absence of pigmented $\mathrm{PH}$, the prepubertal state; stage 2 the initial development of pigmented $\mathrm{PH}$; stages 3 and 4 mark changes in the texture and distribution of $\mathrm{PH}$ and indicate early and late puberty; and stage 5 indicates the mature texture and distribution of $\mathrm{PH}$. Given the difficulty in direct assessment of sexual maturation status in non-medical settings, self-assessments are increasingly used in studies requiring a maturity marker (Malina et al., 2004). This study evaluated the concordance between physician and self-assessments of $\mathrm{PH}$ development in youth soccer players. 


\section{Methods}

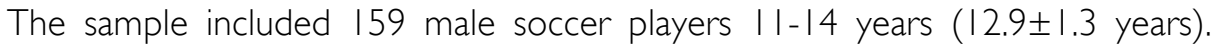
Pubic hair development was assessed by an experience observer using the criteria described by Tanner (1962). For self-evaluation, line drawings taken from photgraphs of standards published by Tanner were provided individually to each boy who was instructed to indicate on the charts the stage that most closely matched his level of sexual maturation. Identical drawings were published by Taylor et al. (200I). Stature and weight were also measured. Concordance between self-assessment and physician examination was assessed for players in two competitive age groups, II-12 and 13-14 years, and also in the total sample. The effect of self- and clinically-assessed stage of $\mathrm{PH}$ on body size was then evaluated.

\section{$\underline{\text { Results }}$}

Distribution of stages of $\mathrm{PH}$ by age group is given in Table I. Concordance between self- and clinical-assessment was lower for players II-12 years (47\%) than for players 13-14 years (76\%), and was 60\% for the total sample. Concordance for specific stages varied by stage as follows: $\mathrm{PHI}, 23 \%$; $\mathrm{PH} 2,90 \%$; $\mathrm{PH} 3,80 \% ; \mathrm{PH} 4,59 \%$. No players were self -assessed in $\mathrm{PH} 5$.

Table I. Cross-tabulation between self- and clinical-assessments of stage of pubic hair development by age group.

\begin{tabular}{|c|c|c|c|c|c|c|c|}
\hline & \multirow{2}{*}{$\begin{array}{l}\text { Clinical } \\
\text { assessment }\end{array}$} & \multicolumn{5}{|c|}{ Self-assessment } & \multirow[b]{2}{*}{-TOTAL } \\
\hline & & $\mathrm{I}$ & 2 & 3 & 4 & 5 & \\
\hline \multirow[t]{6}{*}{$11-12$ yr $(n=87)$} & 1 & 11 & 36 & & & & 47 \\
\hline & 2 & 2 & 25 & 3 & & & 30 \\
\hline & 3 & & 5 & 5 & & & 10 \\
\hline & 4 & & & & & & - \\
\hline & 5 & & & & & & - \\
\hline & Total & 13 & 66 & 8 & - & - & \\
\hline \multirow[t]{6}{*}{$13-14$ yr $(n=72)$} & 1 & & & & & & - \\
\hline & 2 & & 13 & & & & 13 \\
\hline & 3 & & 2 & 23 & & & 25 \\
\hline & 4 & & & 13 & 19 & & 32 \\
\hline & 5 & & & & 2 & & 2 \\
\hline & Total & - & 15 & 36 & 21 & - & \\
\hline \multirow{6}{*}{$\begin{array}{l}\text { Total sample }||-\mid 4 \\
\text { yrs }(n=159)\end{array}$} & 1 & 11 & 36 & & & & 47 \\
\hline & 2 & 2 & 38 & 3 & & & 43 \\
\hline & 3 & & 7 & 28 & & & 35 \\
\hline & 4 & & & 13 & 19 & & 32 \\
\hline & 5 & & & & 2 & & 2 \\
\hline & Total & 13 & 81 & 44 & 21 & - & 159 \\
\hline
\end{tabular}


The influence of stage of puberty on body size by age group is given in Tables 2 and 3. The effect of pubertal status on stature and weight was significant using either clinical- or self-assessed status, and differences in stature and weight were relatively small in players in the two age groups. Regardless of clinical- or self-assessment, the gradient for mean stature and body mass is $\mathrm{PH} 1<\mathrm{PH} 2<\mathrm{PH} 3<\mathrm{PH} 4<\mathrm{PH} 5$.

Table 2. Results of ANCOVA (chronological age as covariate) of stature $(\mathrm{cm})$ and weight $(\mathrm{kg})$ of players $1 \mathrm{I}-12$ years $(n=87)$ by stage of $\mathrm{PH}$ development based on clinical- and selfassessment.

\begin{tabular}{|c|c|c|c|c|c|c|c|c|}
\hline & \multicolumn{4}{|c|}{ Clinical assessment } & \multicolumn{4}{|c|}{ Self-assessment } \\
\hline & $\begin{array}{c}\mathrm{PHI} \\
(\mathrm{n}=47)\end{array}$ & $\begin{array}{c}\mathrm{PH2} 2 \\
(\mathrm{n}=30)\end{array}$ & $\begin{array}{c}\text { PH3 } \\
(n=10)\end{array}$ & $\mathrm{F}$ & $\begin{array}{c}\mathrm{PHI} \\
(\mathrm{n}=13)\end{array}$ & $\begin{array}{c}\mathrm{PH2} 2 \\
(\mathrm{n}=66)\end{array}$ & $\begin{array}{c}\mathrm{PH3} \\
(\mathrm{n}=8)\end{array}$ & $\mathrm{F}$ \\
\hline Stature & 140.9 & 147.5 & 153.7 & $\begin{array}{c}30.795 \\
* * *\end{array}$ & 140.9 & 144.5 & 152.1 & $\begin{array}{c}8.374 \\
* * *\end{array}$ \\
\hline Weight & 34.5 & 41.6 & 44.2 & $\begin{array}{c}26.049 \\
* * *\end{array}$ & 35.1 & 37.9 & 44.2 & $\begin{array}{c}5.736 \\
* * *\end{array}$ \\
\hline
\end{tabular}

$(*) p \leq .05,(* *) p \leq .01$

Table 3. Results of ANCOVA (chronological age as covariate) of stature $(\mathrm{cm})$ and weight $(\mathrm{kg})$ of players $13-14$ years $(n=72)$ by stage of $\mathrm{PH}$ development based on clinical- and selfassessment.

\begin{tabular}{|c|c|c|c|c|c|c|c|c|c|}
\hline & \multicolumn{4}{|c|}{ Clinical assessment } & \multirow[b]{2}{*}{$\mathrm{F}$} & \multicolumn{3}{|c|}{ Self-assessment } & \multirow[b]{2}{*}{$\mathrm{F}$} \\
\hline & $\begin{array}{c}\mathrm{PH} 2 \\
(\mathrm{n}=13)\end{array}$ & $\begin{array}{c}\begin{array}{c}\mathrm{PH} 3 \\
(\mathrm{n}=25)\end{array} \\
\end{array}$ & $\begin{array}{c}\mathrm{PH} 4 \\
(\mathrm{n}=32) \\
\end{array}$ & $\begin{array}{c}\mathrm{PH5} \\
(\mathrm{n}=2)\end{array}$ & & $\begin{array}{c}\mathrm{PH2} \\
(\mathrm{n}=15)\end{array}$ & $\begin{array}{c}\mathrm{PH3} \\
(\mathrm{n}=36)\end{array}$ & $\begin{array}{c}\mathrm{PH} 4 \\
(\mathrm{n}=2 \mathrm{I})\end{array}$ & \\
\hline Stature & 153.6 & 162.2 & 168.2 & 169.4 & $\begin{array}{c}13.075 \\
* * * *\end{array}$ & 154.8 & 164.4 & 168.3 & $\begin{array}{l}14.696 \\
{ }^{*} * * 6\end{array}$ \\
\hline Weight & 43.2 & 52.0 & 59.5 & 61.6 & 11.618 & 44.7 & 55.0 & 59.0 & $\begin{array}{c}11.334 \\
\text { *** }\end{array}$ \\
\hline
\end{tabular}

(*) $p \leq .05,(* *) p \leq .01$

\section{Discussion}

Results suggest that self-assessment of sexual maturity based on charts with illustrations of stage of $\mathrm{PH}$ development is moderately concordant with clinical assessments. Previous research performed by Taylor et al. (200I) noted 49\% agreement between self and clinical assessments using the same protocol in youth 12-16 years of age. Quadratically weighted Kappa statistics for $\mathrm{PH}$ distributions assessed by self and by the physician was $0.67[95 \% \mathrm{Cl} 0.49$ 0.87]. Matsudo \& Matsudo (1994) also studied the concordance of selfassessment and physician evaluation of sexual maturity status (genitals and pubic hair in boys) in 178 males aged 6-26 years. The results showed that 
concordance between self and physician assessments range from $94 \%$ at stage $\mathrm{PHI}$ to $37 \%$ at stage $\mathrm{PH} 2$. Percentages were $62 \%, 86 \%, 79 \%$, respectively at stages $\mathrm{PH} 3, \mathrm{PH} 4, \mathrm{PH} 5$. In addition, better concordance was found for pubic hair (70\% overall concordance) than for the genitals (60\%) and, consequentely, the authors concluded that pubic hair determination was somewhat less subjective than evaluation of the genitals. Regarding selfassessment and physican examination

In the current study as well as that of Matsudo and Matsudo (1994), the magnitude of deviation between self- and clinical-assessments were relatively small and did not exceed one stage. On the other hand, observations of Taylor et al. (200l) on a sample of children attending a paediatric endocrinology outpatient clinic noted a difference of two or more stages between self- and physician-assessment in 12\% of children. Leone \& Comtois (2007) after assessing 24 male elite athletes aged 12 to 17 years, estimated a kappa coefficient of 0.79 .

Observations in the youth soccer players were generally consistent with previously reported results (Schlossberger et al., 1992; Bonat et al., 2002) showing that boys tended to overestimate $\mathrm{PH}$ stage at earlier stages of development. Nevertheless, it is possible that self perception of sexual maturity status may be influenced by a tendency to view one's self as average, i.e., in the mid-range of the distribution, rather than at either extreme of the scale. In addition, physician assessment is not free of error, although this is not ordinarily reported. In the study of Matsudo \& Matsudo (1994), reproducibility of two physician examinations (performed 3 days apart) was 0.89 using spearman rank-order correlation.

Given the relative simplicity and respect for individual privacy, selfassessment is an informative alternative to traditional clinical examination of pubertal status. Nevertheless, self-assessment should be applied in a private in contrast to a group setting. This functions to eliminate comparisons among youth and also to reduce potential embarrassment.

\section{FELS AND TW3 SKELETAL AGES IN ADOLESCENT SOCCER PLAYERS}

Three methods for assessming skeletal maturation are commonly used, the Greulich-Pyle (GP), Tanner-Whitehouse (TW) and Fels methods (see Malina et al., 2004; Beunen et al., 2006). The methods differ in the samples upon which they were based and in criteria. The GP method involves matching specific bones to sex-specific standard plates representing different skeletal ages. The TW and Fels methods use specific verbal criteria for individual 
bones, though the two methods differ in bones used and in statistical basis for assigning skeletal ages. The Fels method also uses ratios of linear measurements of metaphyseal and epiphyseal widths. All three methods result in the assignment of a skeletal age (SA); however, the SAs are not equivalent. Two issues of relevance deal with variation in SAs within specific chronological age (CA) groups and in classification of youth as early, average (on time) or late in skeletal maturity status. These issues are considered in a sample of adolescent soccer players using SAs based on the Fels method and the most recent version of the TW method (TW3).

\section{Methods}

The sample included 72 soccer players 13.3-15.3 years. CA was calculated the difference between date of examination and date of birth as recorded on official birth certificates. Posterior-anterior hand-wrist radiographs of the left hand were taken on all players following a standard protocol. SA was assessed with the Fels (Roche et al., 1988) and the most recent edition of the Tanner-Whitehouse (TW3, Tanner et al., 200I) methods. Players were also classified as late, average (on time) or early on the basis of the difference between SA and CA: Late - SA behind CA by more than 1.0 year; Average (on time) - SA within plus/minus 1.0 year of CA; Early - SA in advance of CA by more than 1.0 year. In addition to descriptive statistics, concordance between maturity groups based on the two methods was tested with the Kappa statistic.

\section{$\underline{\text { Results }}$}

Although CAs ranged from 13.3 to 15.3 years, SAs ranged from 12.0-17.7 years with the Fels method and from 1 1.5-16.4 years with the TW3 method. Variation in SA was almost three times the variation in CA. Mean FELS SA was also greater than mean TW3 SA and the mean SA-CA difference with the FELS method was greater than mean difference with the TW3 method.

Skeletal age with each method of assessment is plotted relative to CA for individual athletes in Figures I and 2. Note that the maximum SA with the TW3 method is 16.4 years which is substantially less than the maximum value determined based on the FELS method. 
Table 4. Chronological and skeletal ages (years) in adolescent male soccer players.

\begin{tabular}{llcccc}
\hline Method of Assessment & Variable & Minimum & Maximum & Mean & $\begin{array}{c}\text { Standard } \\
\text { deviation }\end{array}$ \\
\hline & Chronological age & 13.3 & 15.3 & 14.1 & 0.6 \\
Fels method & Skeletal age & 12.01 & 17.67 & 14.65 & 1.16 \\
& SA-CA & -1.76 & 2.82 & 0.51 & 1.07 \\
& Skeletal age & 11.05 & 16.42 & 14.34 & 1.31 \\
& SA-CA & -2.65 & 2.39 & 0.20 & 1.19 \\
\hline
\end{tabular}

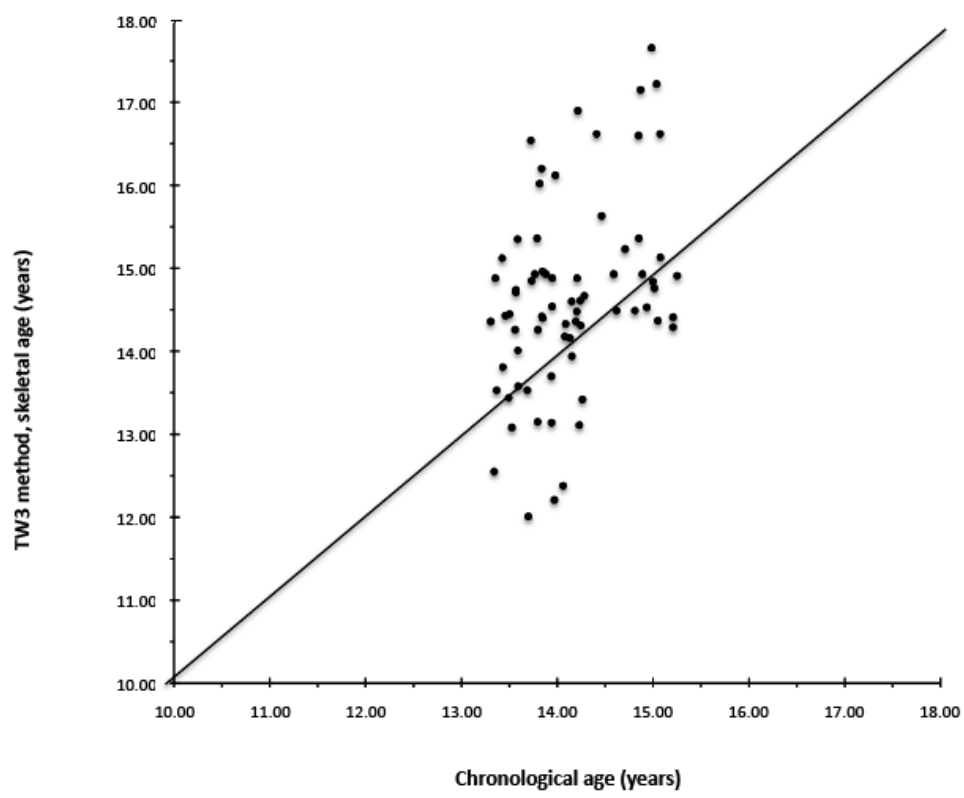

Figure I. TW3 skeletal ages (SA) of individual soccer players plotted relative to their chronological ages (CA). The diagonal line is the line of identity (SA=CA). 


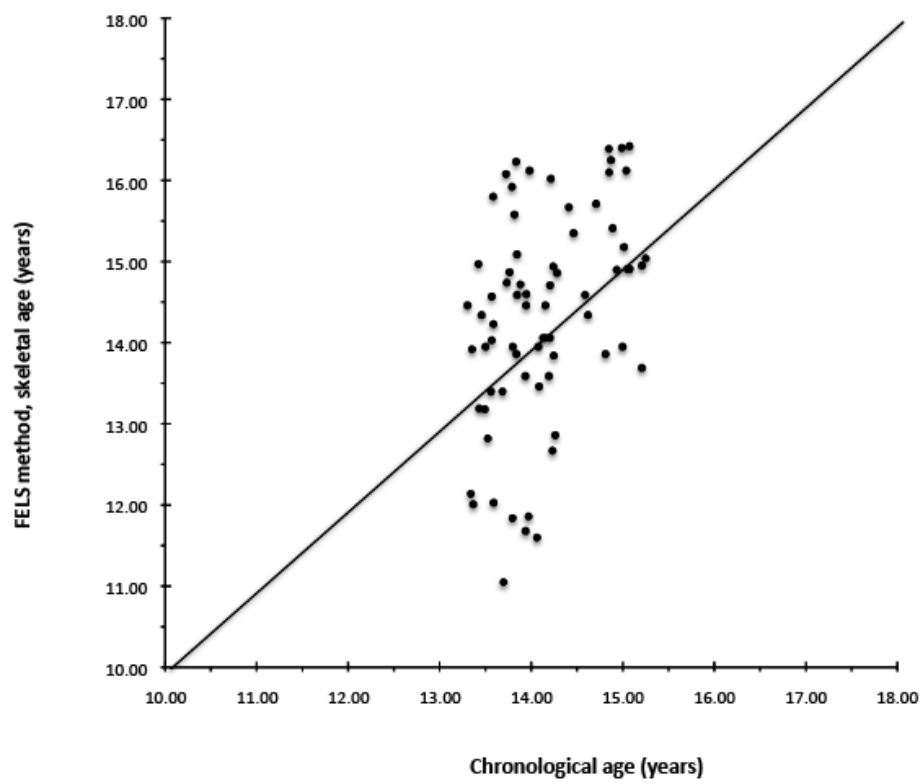

Figure 2. Fels skeletal ages (SA) of individual soccer players plotted relative to their chronological ages (CA). The diagonal line is the line of identity (SA=CA).

Classification of players by maturity status also varied with method of SA assessment: With the TW3 method, the distribution of players by maturity status was as follows: Late, 17\%, On time, 57\%, Early, 26\%. The corresponding distribution with the FELS method was as follows: Late, 5\%, On time, 63\%, Early, 32\%. Concordance between maturity classifications was $81 \%$ (Kappa $=0.65 \pm 0.08, p<0.00 \mathrm{I})$. Figure 3 shows FELS SAs plotted relative to TW3 SAs and Figure 4 shows individual age disparities between methods versus average skeletal age of both assessments.

Table 5. Cross-tabulation between skeletal maturity status based on the Fels and TW3 methods of assessment.

\begin{tabular}{cccccc}
\hline & & \multicolumn{2}{c}{ TW3 } & \\
\cline { 3 - 5 } & & Late & Average & Early & Total \\
\hline \multirow{4}{*}{ FELS } & 4 & & & \\
& Late & 8 & 36 & 1 & 4 \\
& Average & - & 5 & 18 & 23 \\
& Early & & & & \\
\hline & & & 41 & 19 & 72 \\
\hline
\end{tabular}




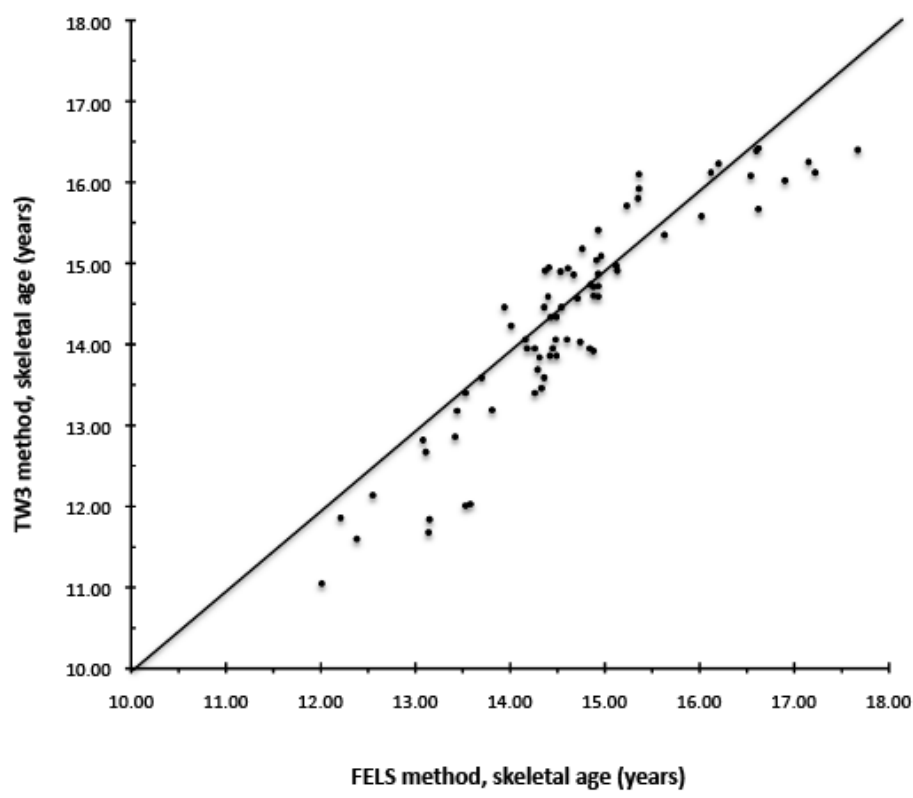

Figure 3. TW3 SAs of individual soccer players plotted relative to their Fels SAs.

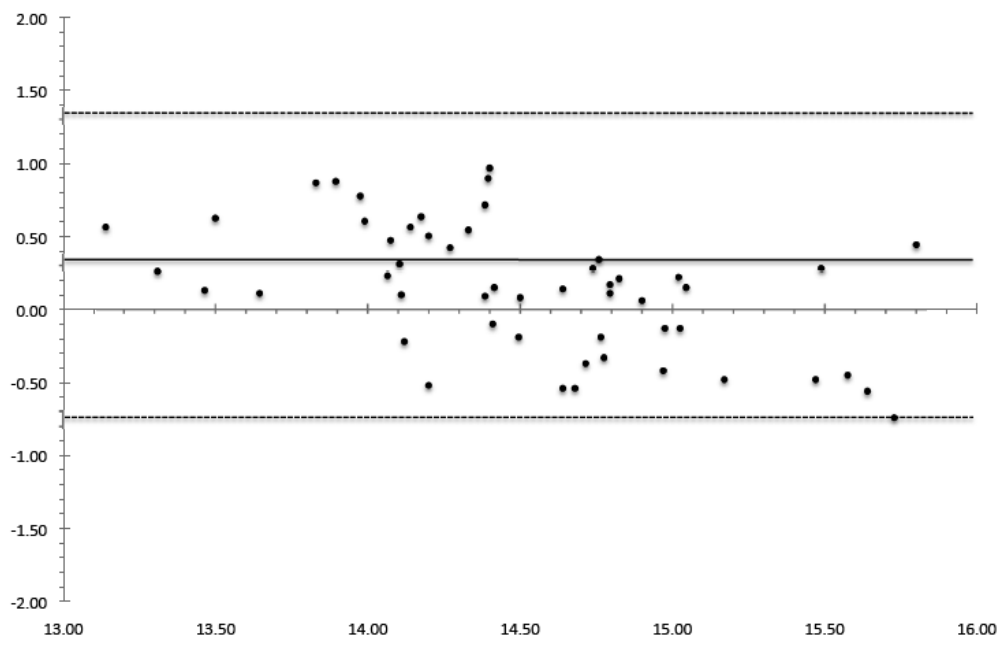

Figure 4. Bland-Altman plot of the age disparity between FELS and TW3 SAs (Yaxis) and mean age based on the two SAs (X-axis). The solid line represents the mean difference and the dashed lines correspond the upper and lower limits of agreement ( 1.96 standard deviations). 


\section{Discussion}

Results of the analysis are generally consistent with other studies of youth soccer players using the TW and Fels methods (Malina, 2003). Earlier studies, however, used the TW2 version of the method which differs from the TW3 revision. The distributions of players by maturity status were reasonably consistent with the Fels and TW3 methods, although more players were classified as late and fewer as average or early with the TW3 method; conversely, fewer players were classified as late and more soccer players were classified as on time and early maturers with the FELS method. This observation is consistent with another study of elite Spanish adolescent soccer players 12.5-16.I years (Malina et al., 2007a).

Differences between SAs obtained by FELS and TW3 methods relates to several factors. The FELS method was developed from a middle class white sample from south-central Ohio in the United States, while TW3 was initially developed on British youth. However, the reference values for the TW3 revision ware derived from samples in four European countries, Argentina, the United States (Texas) and Japan.

The methods also differ in bones of the hand and wrist that are used and in criteria for assessing the level of maturity of each bone. The TW modification provides for radius-ulna-short bone (RUS) and carpal SAs; the 20-bone SA is no longer included. The FELS method utilizes both the long bones of the first, third and fifth digits as well as the carpals in addition to ratios of linear measurements metaphyseal and epiphyseal widths of the long bones. One major difference occurs in the later stage of skeletal maturity which is heavily influenced by the radius. In the TW method, the final stage of the distal radial epiphysis is simply "Fusion of the epiphysis and metaphysis has begun" (Tanner et al. 200 I, p. 63). In the Fels method, capping and fusion of the distal radial epiphysis has four grades for the medial and lateral thirds and three grades for the central third. In addition to differences in criteria for the skeletal maturity in specific indicators, the methods also differ in stastistical weights used to derive SAs. Finally, the third edition of the TW method (TW3) reduced the age of attaining skeletal maturity from 18.0 to 16.5 years in boys, whereas skeletal maturity with the Fels method is at 18.0 years. 


\section{PREDICTING MATURE HEIGHT WITHOUT SKELETAL AGE IN MALE ADOLESCENT HOCKEY PLAYERS}

Percentage of predicted mature height is a potentially useful indicator of maturity status, especially if mature height can be predicted without an estimate of skeletal age. Khamis \& Roche (1994) developed equations for the prediction of mature height (height at 18 years) for the sample of the Fels Longitudinal Study based on American children living in south-central Ohio. The protocol has been used successfully as an estimate of maturity status with youth American football players 9-I 4 years of age (Malina et al., 2005, 2007b). There is a need to compare predicted mature heights with actual mature heights, especially in an independent sample of youth. The present report compared the predicted mature height at an adolescent age with attained mature height.

\section{Methods}

The sample included 80 youth roller hockey players 14.8-16.5 years who were studied in 2002. Height and weight were measured using a portable stadiometer (Harpenden) and a portable balance (Seca model 770) to the nearest $0.1 \mathrm{~cm}$ and $0.1 \mathrm{~kg}$, respectively. Mature height was predicted after Khamis \& Roche (1994) using age, height and weight of the player and midparent height. Heights of both biological parents were measured. Current height of the player was expressed as a percentage of predicted mature height. Heights of the players were measured again at the same time of the year (September-October) in 2006 providing a measure of attained mature height. Heights of the players at the first observation were then expressed as a percentage of attained mature height.

\section{$\underline{\text { Results }}$}

The difference between predicted and attained mature height was $0.95 \pm 1.96$ $\mathrm{cm}$ (median: $1.20 \mathrm{~cm}$, range -3.7 to $+4.0 \mathrm{~cm}$ ). The difference was, on average, less in 15-year-old $(0.30 \pm 1.98 \mathrm{~cm})$ than in 16-year-old $(1.34 \pm 1.85 \mathrm{~cm})$ players. Teenage height was $171.2 \pm 6.3 \mathrm{~cm}$ [ GI5 (15 yrs): $168.5 \pm 5.9 \mathrm{~cm}$; GI6 (I6 yrs): $172.8 \pm 6.0 \mathrm{~cm}$ ] compared to attained mature height, $175.6 \pm 5.2 \mathrm{~cm}$ [G।5: 174.4 $\pm 5.1 \mathrm{~cm} ; \mathrm{Gl}$ : $176.4 \pm 5.2 \mathrm{~cm}$ ]. Teenage height represented $98.0 \pm 1.6 \%$

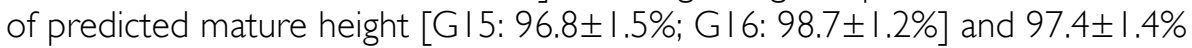

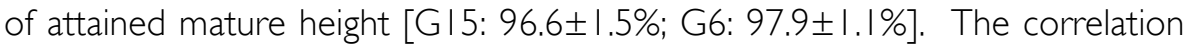
between measured and predicted adult height was $r=+0.93$ [GI5: +0.92; Gl6: +0.94]. 
Table 6. Means, standard deviations and ranges (minimum-maximum) for chronological age, predicted and attained mature height, and adolescent height as a percentage of predicted mature height in hockey players.

\begin{tabular}{|c|c|c|c|}
\hline & $\begin{array}{l}15 \text { yrs } \\
(n=30)\end{array}$ & $\begin{array}{l}16 \text { yrs } \\
(n=50)\end{array}$ & $\begin{array}{c}\text { Total } \\
(n=80)\end{array}$ \\
\hline Chronological age, years & $\begin{array}{l}15.2 \pm 0.2 \\
(14.8-15.4)\end{array}$ & $\begin{array}{l}16.2 \pm 0.4 \\
(15.5-16.4)\end{array}$ & $\begin{array}{l}15.8 \pm 0.6 \\
(14.8-16.4)\end{array}$ \\
\hline $\begin{array}{l}\text { Adolescent Stature, } \mathrm{cm} \\
\text { Stature as \% predicted mature height } \\
\text { Stature as \% measured mature height }\end{array}$ & $\begin{array}{l}168.5 \pm 5.9 \\
96.8 \pm 1.5 \\
96.6 \pm 1.5\end{array}$ & $\begin{array}{l}172.8 \pm 6.0 \\
98.7 \pm 1.2 \\
97.9 \pm 1.1\end{array}$ & $\begin{array}{l}171.2 \pm 6.3 \\
98.0 \pm 1.6 \\
97.4 \pm 1.4\end{array}$ \\
\hline $\begin{array}{l}\text { Predicted mature height,cm } \\
\text { Measured mature height, } \mathrm{cm} \\
\text { Difference }\end{array}$ & $\begin{array}{c}174.1 \pm 4.7 \\
174.4 \pm 5.1 \\
0.3 \pm 1.9\end{array}$ & $\begin{array}{c}175.1 \pm 4.0 \\
176.4 \pm 5.2 \\
1.3 \pm 1.9\end{array}$ & $\begin{array}{l}174.7 \pm 4.9 \\
175.6 \pm 5.2 \\
1.0 \pm 1.9\end{array}$ \\
\hline
\end{tabular}

\section{Discussion}

The current analysis provides evidence that the method of Khamis \& Roche (1994) for predicting mature height without an estimate of skeletal age has reasonable validity in a different population and can be used to derive percentage of mature height as a non-invasive method to assess maturation. Figures 5 and 6 show Bland-Altman plots of the differences between measured and predicted mature heights versus average mature height derived from predicted and measured mature heights in 15 and 16 year old hockey players, respectively. The solid line represents the mean difference and the dashed lines correspond the upper and lower limits of agreement (1.96 standard deviations). 


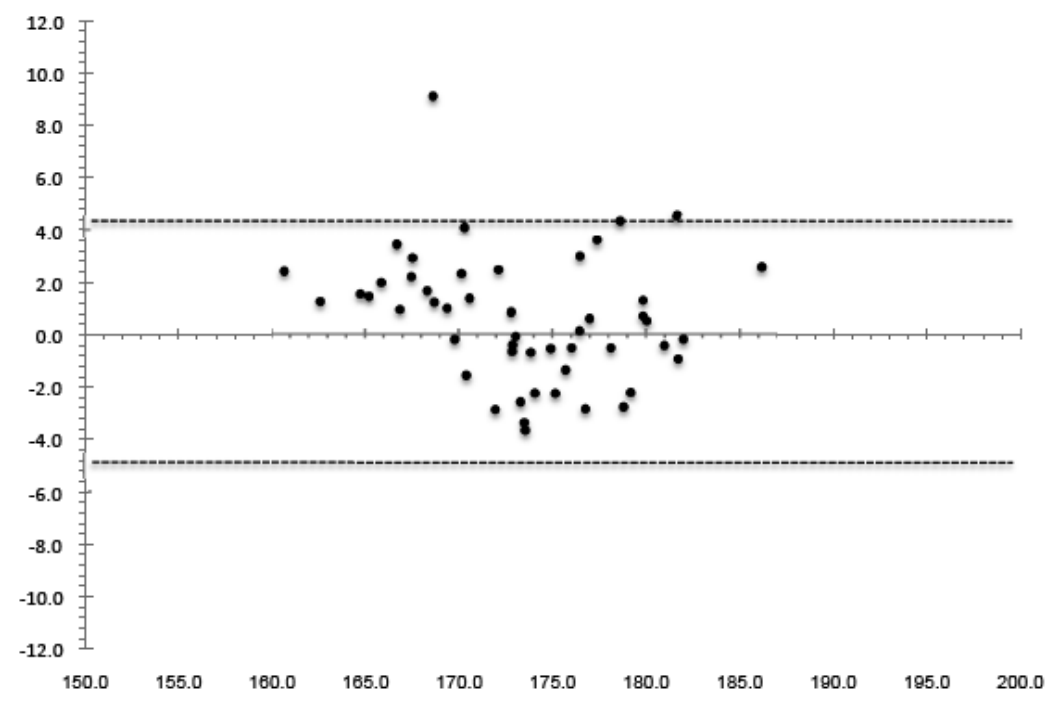

Figure 4. Bland-Altman plot of the differences between predicted and measured mature height relative to the mean based on the two protocols for 15 year old hockey players.

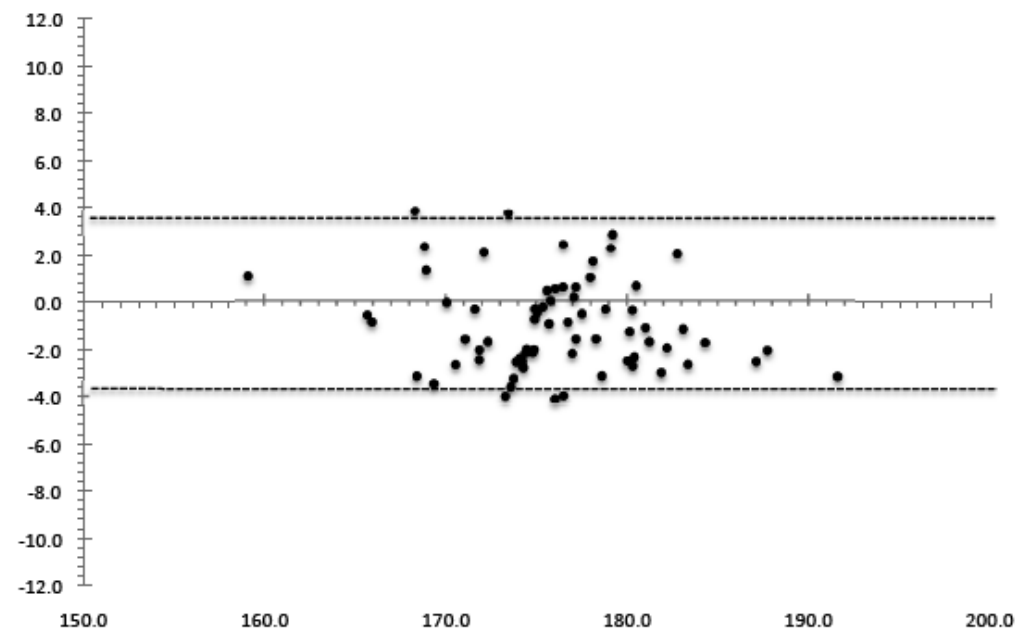

Figure 5. Bland-Altman plot of the differences between predicted and measured mature height relative to the mean based on the two protocols for 16 -year-old hockey players. 
Given the older adolescent age range of the sample of hockey players, their status study as late, average or early maturing based on percentage of predicted mature height attained at the time of the study was not classified. In a study of youth American football players 9-14 years of age, the concordance between classification as late, average or early maturing on the basis of Fels SAs and percentage of predicted mature height attained at the time of the study was moderate (Malina et al., 2007b). Of interest, players discordant for maturity status by the two methods differed in midparent height and percentage of predicted mature height, but did not differ in predicted mature height.

Beunen et al. (1997) proposed another method to predict adult stature (Beunen-Malina method) using five predictors (chronological age, stature, sitting height, subscapular skinfold and triceps skinfold) in adolescent boys 13-16 years of age. The method does not require midparent stature which may be difficult to obtain. The use of predictor variables take into consideration the differential timing of the adolescent spurt in body segments and changes in subcutaneous fat that occur during adolescence. The BeunenMalina method for predicting mature stature was recently validated on longitudinal data from the Madeira Growth Study (Beunen et al., 2007). Correlations between measured and predicted mature height for each cohort $(13,14,15,16$ years $)$ ranged between 0.66 and 0.83 . Average measurement of errors varied from $-1.0 \mathrm{~cm}$ and $+2.5 \mathrm{~cm}$, and the residual standard deviation (measurement error) was between 3.5 and $5.0 \mathrm{~cm}$.

Other methods for predicting mature height use SA as one of the predictors. The method complementary to that of Khamis \& Roche (1994) for the Fels longitudinal sample is that of Khamis \& Guo (1993) which included Fels SA among the predictors of mature height. When both methods, i.e., without and with SA among the predictors, were applied to 87 soccer players I I- 12 years, predicted mature height did not differ substantially in the total sample (Coelho e Silva et al., 2005b). When applied to players at the extremes of height, i.e., the 8 shortest and 8 tallest players in the sample, predicted mature heights with and without SA also did not differ. However, when applied to players at the extremes of skeletal maturity, i.e., 8 least and 8 most skeletally mature players in the $1 \mathrm{I}-12$ year old sample, predicted mature height without SA in the equation was significantly shorter in the least mature players and taller in the most mature players compared to height predicted with SA in the equation (Figueiredo et al., under review). Hence, across a spectrum of size and maturity status, predicting mature height with or without SA among the predictors gives similar means; however, at the extremes of maturity status, the protocols differ, which may have implications for studies using percentage predicted mature height. 


\section{INTEGRATION OF RESULTS OF THE THREE STUDIES}

At the beginning of this chapter, the following question was raised: do different methods of assessing biological maturation during childhood and adolescence provide a similar indication of maturity status? The answer, in general, is yes. This was especially apparent in a longitudinal sample of 177 Polish boys followed from late childhood through adolescence. Ages at attaining 18 indicators of maturity status (ages at attaining peak velocity of growth in height, trunk height, leg length and weight; $80 \% .90 \%, 95 \%$ and $99 \%$ of mature height; stages 2 and 4 of pubic hair and genital development; skeletal maturity (TW2) scores for II through I5 years of age; and take off (initiation) of the growth spurt in height were submitted to a principal components analysis. The results indicated two components; the first was a general maturity factor which accounted for $77 \%$ of the variance, while the second, which accounted for $12 \%$ of the variance, suggested a factor related to skeletal maturation during pre- or early-adolescence (Bielicki et al., 1984).

The ages of the young soccer and roller hockey players in the three studies span early through late adolescence. The first study confirmed a tendency of soccer players I I- 14 years of age to overestimate early stages and to underestimate later stages of pubic hair. Although there was some variation between competitive age groups ( $1 \mathrm{I}-12$ and $13-14$ years), self-assessment tended to be a valid indicator to evaluate differences in body size among boys of contrasting maturity status. The gradient in body size by stage of pubic hair was $\mathrm{PH} 3>\mathrm{PH} 2>\mathrm{PHI}$ and was the same using clinical- or self-assessment.

The second study showed that SAs based on the Fels and TW3 methods were not equivalent in adolescent soccer players. The results reflected in part real inter-individual differences as well as methodological differences. Although variation in skeletal maturity status within a two year competitive age group was considerable, there was reasonable concordance between classifications of players as late, on time and early in maturity status based on the two methods of assessment.

The study of late adolescent hockey players indicated that the Khamis \& Roche (1994) protocol for the prediction of mature (adult) height without an estimate of SA had reasonable validity. As such it merits further study as a non-invasive estimate of biological maturity status in adolescent athletes. 


\section{REFERENCES}

Bayer LM, Bayley N (1959). Growth diagnosis - seleting methods for interpreting and predicting development of one year to maturity. Chicago: University of Chicago Press.

Beunen GP, Malina RM, Lefevre J, Claessens AL, Renson R, and Simons J (1997). Prediction of adult stature and noninvasive assessment of biological maturation. Medicine and Science in Sports and Exercise, 29:225-230.

Beunen GP, Rogol AD, Malina RM (2006). Indicators of biological maturation and secular changes in biological maturation. Food and Nutrition Bulletin, 27 (supplement):S244-S256.

Beunen GP, Malina RM, Freitas DL, Maia JA, Claessens AL, Almeida SM, Gouveia ER, Thomis MA, Marques AT, Lefevre J (2007). Validation of the Beunen-Malina method for the prediction of adult heoght. Acta Kinesiologicae Universitatis Tartuensis, I 2 (supplement):5 I-52.

Bielicki T, Koniarek J, Malina RM (1984). Interrelationships among certain measures of growth and maturation rate in boys during adolescence. Annals of Human Biology 1 1:201-210.

Bonat et al., 2002

Coelho e Silva M, Figueiredo A, Morales J, Roxo A, Malina RM (2005a). Validity of pubic hair self-assessment as an indicator of sexual maturation among pubertal athletes. In Book of Abstracts of the 2005 World Congress of AIESEP - Active Lifestyles: the impact of education and sport, p. 24l.

Coelho e Silva M, Nunes V, Figueiredo A, Malina RM (2005b). Effect of sexual maturity status on current and mature stature estimated with and without skeletal age as a predictor. In N Dikic, S Zivanic, S Ostojic, Z Tornjanski (Eds), Book of abstracs of the $10^{\text {th }}$ Annual Congress of the European College of Sport Science, p 59.

Coelho e Silva M, Moreira de Carvalho $H$, Vaz V, Romeiro J, Figueiredo A, Malina R (2008). Cross-validation of the Khamis-Roche method for the prediction of mature height. In J Cabri, F Alves, D Araújo, J Barreiros, J Diniz, A Veloso (Eds). Book of abstracts of $13^{\text {th }}$ Annual Congress of the European College of Sport Science, p. 233 [ISBN 978-972-735- I 56-5].

Coelho e Silva MJ, Figueiredo AJ, JPena Reyes ME, Malina RM (2009). Skeletal age with FELS and TW3 methods in the assessment of biological maturation among adolescent soccer players. Medicine and Science in Sports and Exercise, $4 \mathrm{I}$ (supplement):S328

Figueiredo AJ, Coelho e Silva MJ, Cumming, SP, Malina RM (under review). Size and maturity mismatches in youth soccer players II I 4 years.

Khamis HJ, Guo S (1993). Improvement in the Roche-Wainer-Thissen stature prediction model: a comparative study. American Journal of Human 


\section{Biology, 5:669-679}

Khamis HJ, Roche AF (1994). Predicting adult stature without using skeletal age: the Khamis-Roche method. Pediatrics, 94:504-507; erratum, 95:457.

Leone M, Comtois AS (2007). Validity and reliability of self-assessment of sexual maturity in elite adolescent athletes. Journal of Sports Medicine and Physical Fitness, 47:361-365.

Malina RM (1994). Physical growth and biological maturation of young athletes. Exercise and Sports Sciences Reviews, 22:389-433.

Malina RM, Bouchard C, Bar-Or O (2004). Growth maturation and physical activity, 2nd edition. Champaign, IL : Human Kinetics.

Malina RM, Cumming SP, Morano PJ, Barron M, Miller SJ (2005). Maturity status of youth football players: a noninvasive method. Medicine and Science in Sports and Exercise, $37: 1044-1052$.

Malina RM, Chamorro M, Serratosa L, Morate F (2007a). TW3 and Fels skeletal ages in elite youth soccer players. Annals of Human Biology, $34: 265-272$.

Malina RM, Dompier TP, Powell JW, Barron MJ, Moore MT (2007b). Validation of a noninvasive maturity estimate relative to skeletal age in youth football players. Clinical Journal of Sports Medicine, 17 :362-368.

Matsudo SM, Matsudo VK (1994). Self-assessment and physician assessment of sexual maturation in Brazilian boys and girls: concordance and reproducibility. American Journal of Human Biology, 6:45 I-455.

Mirwald RL, Baxter-Jones ADG, Bailey DA, Beunen GP (2002). An assessment of maturity from anthropometric measurements. Medicine and Science in Sports and Exercise, 34:689-694.

Nicolson AB, Hanley C (1953). Indices of physiological maturity: derivation and interrelationships. Child Development, 24:3-38.

Roche AF, Tyleshevski F, Rogers E (1983). Non-invasive measurements of physical maturity in children. Research Quarterly for Exercise and Sport, 54:364-37l.

Roche A, Chumlea W, Thissen D (1988). Assessing the skeletal maturity of the hand wrist - FELS method. Springfield, IL: CC Thomas.

Sclosserberger NM, Turner RA, Irwin CE Jr (1992). Validity of self-report pubertal maturation in early adolescents. Journal of Adolescent Health. 13:109-113

Tanner JM (1962). Growth at adolescence, 2nd edition. Oxford: Blackwell.

Tanner JM, Whitehouse RH, Cameron N, Marshall WA, Healy MJR, Goldstein

$H$ (1983). Assessment of skeletal maturity and prediction of adult height, $2^{\text {nd }}$ edition. New York: Academic Press.

Tanner JM, Healy MJR, Goldstein H, Cameron N (200 I). Assessment of skeletal maturity and prediction of adult height (TW3 method), 3rd edition. London: Saunders. 
Taylor SJC, Whicup PH, Hindmarsh PC, Lampe F, Odoki K, Cook DG (200 I). Performance of a new pubertal self-assessment questionnaire - a preliminary study. Paediatric and Perinatal Epidemiology, I5: 88-94.

Partially supported by Fundação para a Ciência e a Tecnologia 